\title{
Current Perspectives on Hypertension and Metabolic Syndrome
}

\author{
George L. Bakris, MD, FACP, FAHA, FASN
}

\begin{abstract}
BACKGROUND: Cardiovascular disease (CVD), which affects 79.4 million Americans, is a relentless problem that continues to grow by leaps and bounds.

OBJECTIVE: To review current perspectives on hypertension and metabolic syndrome.

SUMMARY: Hypertension can be considered a national burden: 1 in 3 American adults are hypertensive, lifetime risk of developing hypertension exceeds $90 \%$, and the total direct costs related to hypertension and its complications approaches $\$ 49.3$ billion. The risk of CVDs doubles for every increment of 20/10 mm of mercury increase in blood pressure (BP), starting at $115 / 75 \mathrm{~mm} \mathrm{Hg}$. Untreated elevated systolic BP may galvanize artery stiffness, and coronary heart disease (CHD) risk rises as systolic BP rises. Thus, emphasis on diastolic pressure as a risk assessment tool can be misleading, particularly in advanced age.

CONCLUSION: Other risk factors for CHD include elevated cholesterol, low high-density lipoprotein cholesterol (HDL-C), smoking, and diabetes. The relative risk of cardiovascular death is increased in hypertensive patients with history of stroke, diabetes, and kidney disease. Finally, metabolic syndrome, consisting of obesity, low HDL-C, and elevated BP, triglycerides, and fasting glucose, affects 47 million people and increases diabetes and CVD risk.
\end{abstract}

KEYWORDS: Cardiovascular disease, Coronary heart disease, Hypertension, Cholesterol, Metabolic syndrome, Diabetes, Blood pressure

J Manag Care Pharm. 2007;13(5):S3-S5

\section{Author}

GEORGE L. BAKRIS, MD, FACP, FAHA, FASN, is a professor of medicine and director, Hypertension Unit, Section of Endocrinology, Diabetes, and Metabolism, University of Chicago-Pritzker School of Medicine, llinois

AUTHOR CORRESPONDENCE: George L. Bakris, MD, Director, University of Chicago, Section of Endocrinology, Diabetes, and Metabolism, 5841 S. Maryland Ave., MC1027, Chicago, IL 60637. Tel: (773) 702-7936; Fax: (773) 834-0486; E-mail: gbakris@earthlink.net Copyright $@ 2007$, Academy of Managed Care Pharmacy. All rights reserved.
$\mathrm{M}$ any Americans - 79.4 million of them—are affected by 1 or more types of cardiovascular disease (CVD). Foremost among cardiac diagnoses is hypertension, affecting 72 million people. Approximately 79 million Americans have had myocardial infarctions (MIs). Coronary heart disease (CHD) affects 15.8 million people, and more than 5 million people have heart failure. ${ }^{1}$ Clearly, CVD is a relentless problem that continues to grow by leaps and bounds.

With 1 in 3 American adults being hypertensive and with the lifetime risk of developing hypertension being greater than 90\%, hypertension can be considered a national burden. ${ }^{1}$ The risk of CVD doubles for every increment of 20/10 mm of mercury in blood pressure (BP), starting at $115 / 75 \mathrm{~mm} \mathrm{Hg.}{ }^{.}$This means that a BP as low as 135/85 mm Hg indicates increased risk. Most patients require 2 or more drugs to reach today's target BP of less than 140/90 mm Hg; those who have diabetes or kidney disease should strive for readings of less than 130/80.2

Estimates of expenditures related to hypertension and its complications in 2007 indicate that total direct costs will approach $\$ 49.3$ billion. ${ }^{1}$ This expenditure's driving forces are medical durables, professional expenses, and hospital expenditures.

According to the Seventh Report of the Joint National Committee on the Prevention, Detection, Evaluation, and Treatment of High Blood Pressure (JNC 7), BP is classified progressively from normal (120/80 $\mathrm{mm} \mathrm{Hg}$ ) to prehypertension (120-139 mm Hg systolic) to stages 1 and 2 hypertension (see Figure 1). This classification represents a change from previous reports in that prehypertension is a new designation. The term itself-prehypertensionwas identified by patients as prompting them to take action. This classification also eliminates stages 3 and 4 hypertension; regardless of how high the BP rises, the strategy is the same once stage 2 is reached. ${ }^{3}$

\section{FIGURE 1 JNC 7 Classification of Blood Pressure}

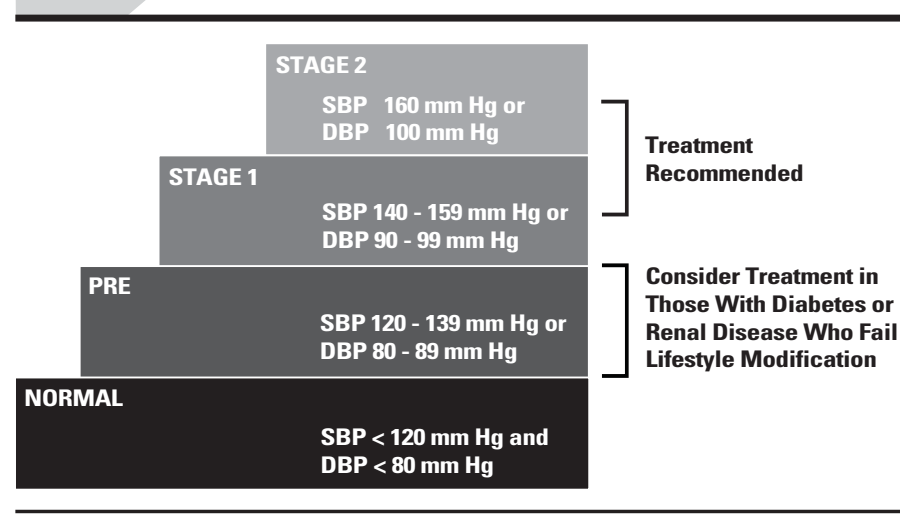

NIH. NHLBI. JNC 7 Report 2004. ${ }^{2}$

DBP = diastolic blood pressure; JNC 7 = Seventh Report of the Joint National Committee on the Prevention, Detection, Evaluation, and Treatment of High Blood Pressure; $\mathrm{SBP}=$ systolic blood pressure. 
Throughout life, systolic (but not usually diastolic) BP increases. ${ }^{4}$ In patients who have passed their 50th birthday, systolic blood pressure (SBP) is critical. Yet, many people at 70 are normotensive if only diastolic blood pressure (DBP) is examined. ${ }^{4}$

The prevalence of isolated systolic hypertension, isolated diastolic hypertension, and combined systolic/diastolic BP varies by age and gender data. Franklin et al. elucidated age-related changes in BP in normotensive and untreated hypertensive subjects using a population-based cohort $(\mathrm{N}=2,036)$ from the original Framingham Heart Study. ${ }^{3}$ After excluding subjects being actively treated for hypertension, they identified a linear rise in SBP from age 30 through 84 years and concurrent increases in DBP and mean arterial pressure. After age 50 to 60 years, DBP decline is consistent with increased large artery stiffness. Untreated elevated SBP may galvanize artery stiffness, creating a vicious cycle. This effect was observed independent of gender. The climb in systolic pressure was more dramatic in older females than in males. In fact, in hypertensive patients aged 65 to 89 years, elevated systolic hypertension predominates regardless of gender. Among patients aged 69 to 80 years, systolic hypertension represents $8 \%$ and $69 \%$ of all hypertension diagnosed in men and women, respectively. ${ }^{5}$ Thus, emphasis on diastolic pressure as a risk assessment tool can be misleading, particularly in advanced age. ${ }^{6}$

\section{Multiple Risk Factors}

The Multiple Risk Factor Intervention Trial (MRFIT) Research Group assessed the combined influence of BP, serum cholesterol level, and cigarette smoking on death from CHD, with a special emphasis on age. Using a large sample ( $\mathrm{N}=316,099 \mathrm{men})$ who had been followed for 12 years, the group identified strong associations between SBP above $110 \mathrm{~mm} \mathrm{Hg}$ and DBP above $70 \mathrm{~mm} \mathrm{Hg}$ and mortality due to CHD, with SBP being a stronger predictor of death than DBP. Patients with BPs of 160/80 mm Hg were at the same risk as those with BPs of $160 / 100 \mathrm{~mm} \mathrm{Hg}$, indicating that a "normal" diastolic pressure was of little consequence. CHD risk rises as SBP rises. ${ }^{7}$

A concurrent diagnosis of diabetes compounds risk. Using data from MRFIT, Stamler et al. examined CVD mortality among 5,163 men who reported taking medication for diabetes. ${ }^{8}$ After 12 years, absolute risk of CVD death among diabetic men was 3 times higher than that of nondiabetic men regardless of age, ethnicity, and other risk factors. For a diabetic, cardiovascular mortality per 10,000 patient-years at any level of BP is a much higher risk than for somebody who is not diabetic.

Research has confirmed a "multiplier effect" for systolic pressure when several risky conditions are present. With kidney disease or end-stage renal disease, the relative risk approaches 2.8. Stroke incurs a relative risk of 2.7 , and coronary disease increases relative risk 1.5 times. ${ }^{9-11}$ So systolic pressure drives cardiovascular risk as gasoline fuels fire.

The 10-year risk for CHD is clearly associated with SBP and is further influenced by other risk factors: elevated cholesterol, low

\section{FIGURE 2 Atherogenic Consequencs of Metabolic Syndrome}

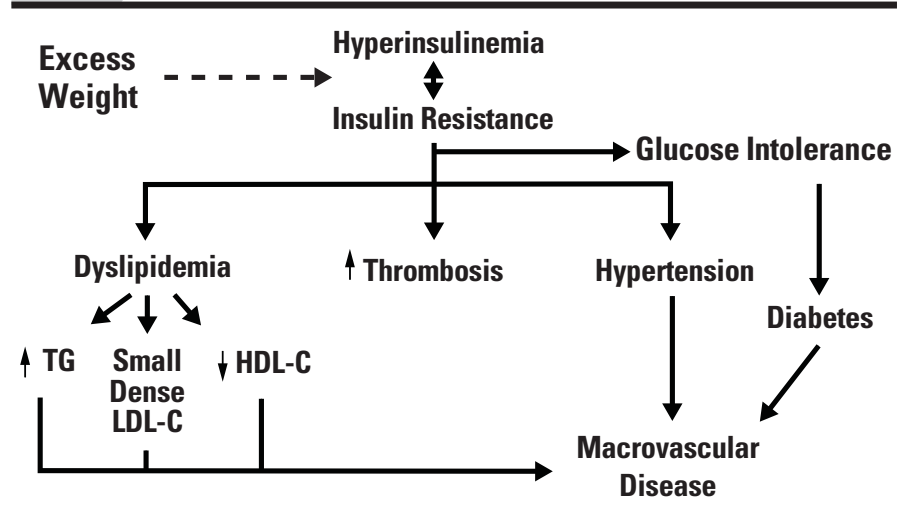

HDL-C = high-density lipoprotein cholesterol; $L D L-C=$ low-density lipoprotein cholesterol; $T G=$ triglyceride.

high-density lipoprotein cholesterol (HDL-C), smoking, and diabetes. Clinicians must examine each individual's entire risk profile. $^{12}$

\section{Add Obesity to the Mix}

Obesity is an issue unto itself, and metabolic syndrome is a growing concern. Obesity is now considered epidemic, and metabolic syndrome is an interplay of lipids, BP, and obesity. Forty-seven million people have metabolic syndrome. The diagnosis requires 3 or more of the following: obesity, low HDL-C, a BP in the prehypertensive range above 130/85 $\mathrm{mm} \mathrm{Hg}$, elevated triglycerides, and elevated fasting glucose..$^{13}$ Metabolic syndrome increases diabetes and CVD risk. Mexican Americans have the highest ageadjusted prevalence (31.9\%) of metabolic syndrome, followed by whites (23.8\%) and African Americans (21.6\%), who have similar incidences within their populations. ${ }^{2}$

Obesity is a real problem, wherein $5 \%$ of males aged 12 to 19 years have metabolic syndrome, doubling in prevalence to more than 10\% in males aged 30 to 39 years and reaching $45 \%$ in males aged 60 to 69 years. Approximately one third of Americans between the ages of 50 and 59 years of both genders have metabolic syndrome. ${ }^{14,15}$ Figure 2 demonstrates how the atherogenic consequences of metabolic syndrome are blatant. Excessive weight causes insulin resistance (difficulty using insulin in the periphery for metabolism).

Insulin becomes elevated with obesity because higher insulin levels are necessary to send glucose into the cells. The beta cells in the pancreas become exhausted, increasing the risk of diabetes. Elevated serum fat content leads to dyslipidemia. The triad of hypertension, elevated lipids, and elevated risk for diabetes contributes to inflammation and accelerated risk of developing atherosclerosis. 


\section{DISCLOSURES}

This article is based on a presentation funded by an educational grant from Forest Pharmaceuticals. The author discloses that he has received honoraria from Forest Pharmaceuticals for participation in this supplement. He discloses the following commercial/financial relationships through grant/research support, consultant services, speakers bureaus, and/or advisory boards: AstraZeneca, Abbott, Boerhinger-Ingelheim, BMS/ Sanofi-Aventis, Kos, GlaxoSmithKline, Merck, Novartis, Lilly, Walgreens (Formulary Committee), NIH (NIDDK/NHLBI), and Atlas Foundation.

\section{REFERENCES}

1. American Heart Association and American Stroke Association. Heart disease and stroke statistics—2007 update. Available at: www.americanheart.org/ downloadable/heart/1166712318459HS_StatsInsideText.pdf. Accessed March 16, 2007.

2. The National Institutes of Health and the National Heart, Lung and Blood Institute. The Seventh Report of the Joint National Committee on Prevention, Detection, Evaluation, and Treatment of High Blood Pressure; 2004. Available at: www.nhlbi.nih.gov/guidelines/hypertension/jnc7full.pdf. Accessed March 17, 2007.

3. Franklin SS, Gustin W IV, Wong ND, et al. Hemodynamic patterns of agerelated changes in blood pressure. The Framingham Heart Study. Circulation. 1997:96:308-15.

4. Galarza CR, Alfie J, Waisman GD, et al. Diastolic pressure underestimates age-related hemodynamic impairment. Hypertension. 1997;30:809-16.

5. Kannel WB. Framingham study insights into hypertensive risk of cardiovascular disease. Hypertens Res. 1995;18:181-96.

6. Chobanian AV, Bakris GL, Black HR, et al.; National Heart, Lung, and Blood Institute Joint National Committee on Prevention, Detection, Evaluation, and Treatment of High Blood Pressure; National High Blood Pressure Education Program Coordinating Committee. The Seventh Report of the Joint National Committee on Prevention, Detection, Evaluation, and Treatment of High Blood Pressure: the JNC 7 report. JAMA. 2003;289:2560-72.
7. Neaton JD, Wentworth D. Serum cholesterol, blood pressure, cigarette smoking, and death from coronary heart disease. Overall findings and differences by age for 316,099 white men. Multiple Risk Factor Intervention Trial Research Group. Arch Intern Med. 1992;152:56-64.

8. Stamler J, Vaccaro O, Neaton JD, Wentworth D. Diabetes, other risk factors, and 12-yr cardiovascular mortality for men screened in the Multiple Risk Factor Intervention Trial. Diabetes Care. 1993;16:434-44.

9. Kannel WB. Risk stratification in hypertension: new insights from the Framingham Study. Am J Hypertens. 2000;13(1 pt 2):3S-10S.

10. Klag MJ, Whelton PK, Randall BL, et al. Blood pressure and end-stage renal disease in men. N Engl J Med. 1996;334:13-18

11. Perry HM Jr, Miller JP, Fornoff JR, et al. Early predictors of 15-year endstage renal disease in hypertensive patients. Hypertension. 1995;25(4 pt 1):587-94.

12. Chobanian AV, Bakris GL, Black HR, et al; Joint National Committee on Prevention, Detection, Evaluation, and Treatment of High Blood Pressure. National Heart, Lung, and Blood Institute; National High Blood Pressure Education Program Coordinating Committee. Seventh Report of the Joint National Committee on Prevention, Detection, Evaluation, and Treatment of High Blood Pressure. Hypertension. 2003;42:1206-52.

13. Grundy SM, Cleeman JI, Daniels SR, et al. Diagnosis and management of the metabolic syndrome. An American Heart Association/National Heart, Lung, and Blood Institute Scientific Statement. Circulation. 2005;112:2735-52.

14. Ford ES, Giles WH, Dietz WH. Prevalence of the metabolic syndrome among US adults: findings from the third National Health and Nutrition Examination Survey. JAMA. 2002;287:356-59.

15. Cook S, Weitzman M, Auinger P, Nguyen M, Dietz WH. Prevalence of a metabolic syndrome phenotype in adolescents: findings from the third National Health and Nutrition Examination Survey, 1988-1994. Arch Pediatr Adolesc Med. 2003;157:821-27. 